\title{
Rendición social de cuentas en España. El papel de las organizaciones de la sociedad civil en la promoción de buena gobernanza durante la pandemia derivada de la COVID-19
}

\author{
Social Accountability in Spain. The role of civil society organizations \\ in promoting good governance during the COVID-19 pandemic
}

\author{
MANUEL VILLORIA \\ Universidad Rey Juan Carlos \\ FERNANDO JIMÉNEZ \\ Universidad de Murcia

\section{Cómo citar/Citation} \\ Villoria, Manuel y Jiménez, Fernando (2021). Rendición social de cuentas en España. El papel de las organizaciones \\ de la sociedad civil en la promoción de buena gobernanza durante la pandemia derivada de la COVID-19. \\ Revista Española de Ciencia Política, 57, 111-137. Doi: https://doi.org/10.21308/recp.57.04
}

\section{Resumen}

El éxito en la construcción de buena gobernanza necesita de la confluencia de, al menos, tres variables: a) una coyuntura crítica; b) reformas iniciales que generen organizaciones de accountability horizontal, y c) una coalición de diversas fuerzas políticas y sociales con suficiente capacidad para superar los obstáculos de la acción colectiva y los puntos de veto del sistema. Este trabajo indaga en la labor de las organizaciones no gubernamentales (ONG) en esa coalición durante la pandemia provocada por la COVID-19. Utilizando una metodología propia del enfoque de la grounded theory, se usaron dos conceptos de sensibilización: el de buena gobernanza y el de social accountability. Con todo ello, se pudieron identificar veinte ONG para narrar la actividad de control sobre la integridad de la gobernanza en Espańa. Se definió como unidad de estudio objetivo las campañas y, tras un análisis teórico y de revisión de literatura, se identificó qué se podía considerar éxito en este tipo de actividades de control social. Finalmente, desde la propia visión de los sujetos de estudio, se analizaron dos campañas desarrolladas durante la pandemia. En ellas se pudo comprobar la importancia que dan las ONG a un enfoque estratégico frente a la mera confrontación, y muy esencialmente, la importancia de trabajar en coalición interna y con los actores públicos dedicados a labores de accountability horizontal.

Palabras clave: rendición de cuentas social, grupos de interés, buena gobernanza, sociedad civil, COVID-19, campañas, redes de políticas, grounded theory, rendimientos, gobierno abierto. 


\begin{abstract}
Success in building good governance requires the confluence of at least three variables: a) a critical juncture; b) initial reforms to generate horizontal accountability organizations; and c) a coalition of diverse political and social forces with sufficient capacity to overcome the collective action obstacles and the veto points of the system. This article investigates the work developed by NGOs in this coalition during the pandemic caused by COVID-19. Following the grounded theory approach, two sensitization concepts were used, namely, "good governance» and «social accountability». With all this, twenty NGOs were identified to narrate the control on governance integrity in Spain. Campaigns were defined as the target unit of study and, after a theoretical analysis and literature review, the understanding of success in this type of social control activities was established. Finally, two campaigns developed during the pandemic were analyzed from the NGOs' point of view. These campaigns showed the importance that NGOs in this field give to a strategic approach instead of mere confrontation and, more in particular, the importance of working in an internal coalition and with public actors engaged in horizontal accountability.

Keywords: social accountability, lobbies, good governance, civil society, COVID-19, campaigns, policy networks, grounded theory, performance, open government.
\end{abstract}

\title{
INTRODUCCIÓN
}

Partiendo de la multicitada teoría de Tocqueville (1969) sobre el papel del asociacionismo ciudadano en la consolidación de pautas de civismo, existen numerosos estudios que indican que la presencia de una sociedad civil fuerte, expresada en un denso tejido asociativo, es un ingrediente esencial para la democratización y la salud de la democracia, para el buen funcionamiento de la economía y para la propia eficacia del gobierno (Putnam, 1993, 1995; Keck y Sikkink, 1998). Una sociedad civil fuerte, por otra parte, puede movilizar a la ciudadanía en la defensa de causas de interés público. Por ello, puede ser un contrapoder frente a gobiernos autoritarios o corruptos, según otra variante de la teoría de la sociedad civil (Sociedad civil II en la terminología de Foley y Edwards, 1996: 39). Vinculada a esta visión benevolente de la sociedad civil, el concepto de rendición de cuentas social, en sus diferentes modalidades, defiende que la promoción de vías de control por parte de la sociedad civil sobre la actuación de los poderes públicos y privados es un componente positivo de la gobernanza (Peruzzotti y Smulovitz, 2006). O'Donnell, por su parte, considera que la sociedad civil, gracias al control social, y en interacción con la accountability vertical y horizontal, puede contribuir a una gobernanza que se desarrolle para el bien común (O’Donnell, 2006, 2007: 135 y ss.).

El éxito en la construcción de buena gobernanza necesita de la confluencia de, al menos, tres variables: una coyuntura crítica que pueda quebrar los equilibrios puntuados (Jones y Baumgartner, 2005); reformas iniciales que generen organizaciones de accountability horizontal que puedan actuar como palancas de la renovación, 
y una coalición de diversas fuerzas políticas y sociales con suficiente capacidad para superar los obstáculos de la acción colectiva y los puntos de veto del sistema (Tsebelis, 2000; Sabatier, 1998). La confluencia de las tres se da raramente y, por ello, es difícil ver grandes avances en la buena gobernanza globalmente. Nuestra hipótesis es que, en el caso español, actualmente se pueden dar dos de las variables que ayudarían a las reformas. Existe una coyuntura favorable para grandes reformas, en el marco de la denominada estrategia de reconstrucción post-COVID, y existen también ciertas instituciones públicas que están promoviendo cambios y mejoras, desde la AIREF hasta las agencias anticorrupción autonómicas, donde existen. Pero sabemos bastante poco del trabajo de la sociedad civil en este combate por una mejor gobernanza. Este trabajo trata de indagar en esta labor, en un momento muy especial como es el de la pandemia provocada por la COVID-19. Con ello, este trabajo se sitúa también en el marco de los estudios sobre el papel de los grupos de interés, en concreto de los denominados advocacy groups en el sistema político español (ver Molins et al., 2016).

Hablar del éxito de movimientos sociales en este u otro tipo de políticas es muy complejo (Baldwin, 2000). Además, es muy contextual: no es lo mismo el éxito en países en vías de desarrollo y con corrupción sistémica que en países desarrollados de corrupción baja o media-baja. En los primeros, la clave suele estar en proteger a la gente, deteniendo la demanda de sobornos por la burocracia, sobre todo la policía (ver Landell-Mills, 2013); en los segundos, el éxito está más vinculado a fortalecer el marco institucional y asegurar la implementación de reformas. Normalmente, la unidad de estudio para analizar el trabajo de los movimientos sociales desde su propia narrativa es la campaña. Al analizar las campañas optamos por una forma de analizar los grupos de interés más cercana al modelo estadounidense — centrado en las tácticas de influencia - que en los estudios europeos — con foco en las políticas públicas resultantes- (Mahoney y Baumgartner, 2008). El concepto de campaña es muy debatido. De acuerdo con Ackerman y Kruegler (1994: 10-11), podríamos definir una campańa como una serie de tácticas continuas y observables que persiguen un objetivo político. Puede durar desde días a años. En todo caso, exigen liderazgo (Chenoweth y Stephan, 2011).

Si queremos hablar de éxito de una campaña, ésta debería reunir dos condiciones: la primera es que alcance plenamente los objetivos señalados (por ejemplo, que se adopte una legislación que proteja a los denunciantes de corrupción) en un año a partir del pico de actividad; la segunda, que ese impacto sea resultado directo de las actividades realizadas en la campaña (Pape, 1997). Las campañas tienen siempre un objetivo claro y, por ello, identifican bien a los oponentes para vencer sus resistencias a través del apoyo público y el uso de las redes. Esto las diferencia de movimientos espontáneos de protesta, que no tienen estrategia y atacan oponentes de forma indiscriminada. La indiscriminación en el ataque hace que se pierda más fácilmente el apoyo social (Chenoweth y Stephan, 2011). En todo caso, una campaña para combatir la corrupción o para mejorar la gobernanza de un país tiene enormes dificultades para medir impactos, pues estos requieren continuidad y un plazo de análisis largo, aunque se puedan medir algunos outputs dispersos, como luego veremos. 
En este trabajo trataremos de analizar cómo las ONG, de acuerdo con su relato, se esfuerzan en diseñar la agenda pública relacionada con la política de buena gobernanza - aunque difícilmente se pueda unificar en una agenda común algo tan amplio como la buena gobernanza-, y cómo hacen seguimiento de los programas gubernamentales vinculados a tal política durante un momento histórico disruptivo como es el de la pandemia por la COVID-19. Pero no trataremos, como ya hemos anticipado, de medir impactos finales de las campańas emprendidas en la buena gobernanza, aunque sí controlaremos éxitos en el cumplimiento de objetivos específicos de las mismas, al menos desde la perspectiva de las propias ONG. Lo que veremos a partir de ahora es una explicación del enfoque y método elegido; una clarificación conceptual y una revisión teórica sobre cómo entender y medir el éxito de las organizaciones sociales en la lucha por una mejor gobernanza. Finalmente, antes de las conclusiones, siguiendo el modelo de análisis generado previamente, presentaremos una breve descripción de las principales actuaciones en época de pandemia de las ONG que promueven la buena gobernanza. En concreto, nos centramos en algunas campañas que denunciaron actuaciones, amparadas en la lucha contra la pandemia, que podían dañar la buena gobernanza y, con ello, la calidad de la democracia. En segundo lugar, atendemos también a campañas desarrolladas en el marco de la pandemia, pero que tienen orígenes y proyección más amplia: la presencia en la generación del IV Plan de Gobierno Abierto, y la campańa por la aprobación de una ley que proteja a los alertadores de actos ilícitos. Estas últimas campañas se sitúan dentro del tiempo de la pandemia, pero no son consecuencia de la misma.

\section{ENFOQUE Y METODOLOGÍA}

En este artículo partimos de la base de que no existe una crisis de legitimidad en Espańa, que es la que se daría cuando las creencias de la sociedad chocaran con las ideas dominantes en el texto constitucional y en la forma de gobierno recogida en la literatura oficial (Rosa, 2020; Montero et al., 1998). Tampoco creemos que exista un problema de alienación generalizada, que es la que ocurriría «cuando las normas, las metas o los fines que definen las instituciones públicas comienzan a parecer irrelevantes» (Taylor, 1979: 90), al no responder a las expectativas, necesidades y creencias de la gente. Este segundo supuesto es el de la crisis institucional. Cuando esto se produce, la alienación entre prácticas sociales y creencias individuales genera una patología social que puede dar lugar a fenómenos de anomia. En todo caso, fuera de estos supuestos de crisis profunda, las instituciones necesitan ser coherentes con los valores que proclaman si quieren legitimarse y obtener la confianza social. El objetivo de este trabajo es describir y analizar las narrativas de los miembros de organizaciones de la sociedad civil implicados en la búsqueda de la coherencia entre normas y praxis en las instituciones gubernamentales. Como indica O’Donnell (2006: 335), la rendición de cuentas social no busca denunciar el mal funcionamiento de servicios y la restitución material correspondiente; su misión principal es la solicitud de respeto a diversos 
derechos civiles y sociales y la demanda de que las acciones gubernamentales resulten apegadas a la legalidad.

Las narrativas de las ONG no se pueden analizar en un vacío, en su mero carácter declarativo, sino en su conexión con el contexto y con las estrategias y acciones para alcanzar buena gobernanza. Qué hacen las ONG, qué entienden por prioritario, cómo superan problemas de acción colectiva y mantienen la movilización del grupo en el tiempo (ver Tarrow, 1998), cómo desarrollan sus campañas, qué influencia han logrado en este tiempo de pandemia son preguntas que intentaremos responder en estas breves páginas.

Para responder a dichas preguntas, se ha seguido una estrategia de investigación cualitativa sostenida en el potencial de la grounded theory para el estudio de los movimientos sociales (Mattoni, 2014; 2020). Nuestro método de medición de influencia se basa esencialmente en la autoestimación por el propio grupo del grado de éxito en el cumplimiento de sus objetivos, mediante encuestas y entrevistas, lo que permite analizar varios casos al tiempo (Dür y De Brièvre, 2007). Ello supuso seleccionar un sensitizing concept que nos sugiriera una dirección en la que buscar los actores y casos con los que trabajar. Este concepto, tras analizar documentación y noticias relevantes fue el de buena gobernanza. Un concepto que no está cerrado, que es abierto, pero que nos permite identificar toda una serie de experiencias de activismo en los que la sociedad civil se moviliza para promover valores como la transparencia, la rendición de cuentas, la integridad o la legalidad, sobre todo en el sector público, pero sin dejar de lado el sector privado. Con este concepto de sensibilización pudimos seleccionar veinte actores (ver tabla 1) y más de sesenta casos que nos han permitido construir (es parte de otra investigación), a través de la comparación de datos similares en casos semejantes (Glaser y Strauss, 1967), códigos comunes que refuerzan las bases teóricas de estos estudios.

En este texto solo se tratarán dos de los casos analizados, por ser relevantes y situarse específicamente dentro del periodo de pandemia. También se utilizó el concepto de rendición de cuentas social como concepto de sensibilización, aunque nos abría un abanico de actores excesivamente amplio, pues no hay que olvidar que, en ese concepto, según Peruzzotti y Smulovitz (2006), se incluyen todo tipo de asociaciones cívicas, ONG y movimientos sociales, así como los medios de comunicación y los ombudsman. Cruzando los dos conceptos, nos centramos en ONG que, a través del control social y sus métodos, promovieran la transparencia, la legalidad y la integridad; en esencia, la buena gobernanza.

Se intentó realizar la selección de los actores más relevantes con base en datos objetivos; eso sí, una vez eliminados actores que, aunque participaran en acciones de denuncia y control del comportamiento político, eran empresas, como Maldita y Newtral, sindicatos más representativos (como UGT o CC. OO.) o, más excepcionalmente, grupos criminales (como Manos Limpias). Para ello se discriminó, primero, por la presencia y referencias en redes sociales; segundo, por su impacto en medios de comunicación; tercero, por la autorreferencia entre asociaciones, que llevaba a que un conjunto de ONG fuera mencionado como relevante por las propias asociaciones de 
forma repetida; cuarto, por sus productos y el uso de estos social y académicamente ${ }^{1}$. De forma coherente con la estrategia y métodos elegidos, hemos realizado ocho entrevistas en profundidad a miembros relevantes de las asociaciones seleccionadas, todas ellas vinculadas a la lucha contra la corrupción y la promoción de transparencia y cultura de la legalidad. Estas entrevistas se han enriquecido con una encuesta a las propias asociaciones (han contestado quince de ellas, las otras cinco han sido entrevistados sus directivos), buscando corroborar lo que diversas metaevaluaciones señalaban como éxito en el control social. Además, se ha incorporado observación participante y se han leído documentos y memorias de las propias asociaciones (Patton, 2002). Por una vía u otra, creemos tener información suficiente de todas ellas. Esta información ha sido la base para desarrollar códigos que se han ido depurando tras la recepción inicial y consolidando en memos que nos dieran una narrativa coherente con lo que los actores percibían (Strauss y Corbin, 1998). El objetivo final es generar una teoría que aporte explicaciones coherentes de qué, cómo y por qué actúan estos sectores de la sociedad civil y hasta qué punto consiguen influir en la configuración legitimante de las instituciones. Una teoría que no reifica, que no asume significados universales, sino situados en el entorno y en la narrativa propia de sus actores.

TABLA 1.

ONG ANALIZADAS ${ }^{2}$

\begin{tabular}{l}
\hline+ Democracia \\
\hline Acces Info Europe \\
\hline Asociacin de Profesionales de las Relaciones Institucionales (APRI) \\
\hline Asociación de Sujetos Obligados en Prevención del Blanqueo de Capitales \\
\hline Asociación Española de Acreditación de la Transparencia (ACREDITRA) \\
\hline Asociación Española de Compliance (ASCOM) \\
\hline Asociación Nacional de Afectados por Delitos Económicos e Impagos \\
\hline Blue Print for Free Speech \\
\hline Confederación Intersindical de Crédito (CIC) \\
\hline Corruptil \\
\hline Ecologistas en Acción
\end{tabular}

1. Tras una posterior revisión, se comprobó que quedaron fuera algunas organizaciones que, probablemente, deberían haber sido incorporadas; aun así, tras analizar sus aportaciones se llegó a la conclusión de que su área de influencia ya estaba recogida por otra ONG mayor y que volver a realizar la encuesta no modificaría esencialmente el resultado final.

2. Trece de las quince asociaciones son de ámbito nacional y solo dos de ámbito autonómico; cuatro son, además, internacionales o forman parte de redes internacionales (tres de ámbito mundial y la otra de ámbito europeo). Son independientes de partidos y Administraciones (salvo una que es una fundación con participación pública). 


\begin{tabular}{l} 
Fibgar \\
\hline Fundación Carles Pi i Sunyer. d'Estudis Autonòmics i Locals \\
\hline Fundación Ciudadana Civio \\
\hline Fundación Compromiso y Transparencia \\
\hline Fundación Hay Derecho \\
\hline Observatorio DESC \\
\hline Taula d'Entitats del Tercer Sector Social de Catalunya \\
\hline Transparency International Espańa \\
\hline XNet
\end{tabular}

Fuente: elaboración propia.

\section{MARCO CONCEPTUAL Y ANALÍTICO}

En este texto conectamos la idea de sociedad civil con la idea de control del poder estatal y del mercado. Entendemos la sociedad civil como «una esfera de interacción situada entre la economía por una parte y el Estado, por otra, compuesta sobre todo por la esfera íntima (especialmente la familia), la esfera de las asociaciones (especialmente las organizaciones voluntarias), los movimientos sociales y las formas de comunicación pública» (Cohen y Arato, 1992: IX). Una idea de sociedad civil que surge fundamentalmente de la lucha contra los regímenes autoritarios tanto en Europa del Este como en Latinoamérica (Glasius, 2012), pero que encuentra su fundamento teórico en su conexión con el ideal de la esfera pública. La esfera pública se sitúa en la sociedad civil y es el lugar donde las personas pueden debatir asuntos de interés mutuo como compañeros, y conocer los hechos, los acontecimientos y las opiniones, los intereses y las perspectivas de los demás en una atmósfera libre de coacciones y de desigualdades (Habermas, 1987). Este concepto nos permite huir de la concepción apolítica de la sociedad civil propia de Putnam $(1993,1995)$, pues entendemos que lo que genera compromiso cívico es la pertenencia a asociaciones que defienden la esfera pública y promueven el control sobre el poder del sistema. Al tiempo, rechaza la visión negativa de la sociedad civil, pues esta no surge para la defensa de intereses económicos ni partidistas, sino que, a través de la deliberación democrática, busca contribuir a solucionar problemas comunes de la comunidad y/o proteger el mundo de la vida. Creemos que las organizaciones seleccionadas responden a esta visión de la sociedad civil.

Por su parte, el concepto de rendición de cuentas social podría tener sus primeras configuraciones en estudios de gestión pública, en los que se insiste en la presencia de la sociedad civil en la provisión de servicios, bajo la metáfora de que es mejor para la calidad de los servicios públicos que el Estado lleve el timón en lugar de remar directamente (Osborne y Gaebler, 1992). Y se sistematizan, con una visión más politológica, en investigaciones centradas en países con instituciones y Gobiernos débiles, poniendo 
el énfasis en el control de políticos y funcionarios por los ciudadanos, las comunidades, la prensa independiente y las organizaciones de sociedad civil (Malena et al., 2004; Peruzzotti y Smulovitz, 2006). En la actualidad, se puede concebir como un paraguas conceptual en evolución que incluye: el seguimiento y la supervisión por parte de los ciudadanos de la actuación pública y/o privada, sistemas de acceso y difusión de información pública centrada en el usuario, sistemas de acceso/difusión de quejas y reclamaciones, así como la participación de los ciudadanos en la toma de decisiones sobre la asignación de recursos, como los presupuestos participativos (Fox, 2015: 343). En cualquier caso, como ya indicamos previamente, la rendición de cuentas social funciona mejor cuando los otros sistemas de accountability funcionan también bien, especialmente cuando el sistema judicial y el de accountability horizontal se activan y las demandas de la sociedad civil los llevan a actuar paralizando y sancionando los abusos de poder, las ilegalidades o la corrupción (Fox, 2007). En este texto, nos vamos a centrar en la rendición de cuentas social realizada por organizaciones de la sociedad civil suficientemente consolidadas que busquen el control del poder y promuevan la buena gobernanza.

El concepto de buena gobernanza es muy debatido. La nueva gobernanza consiste en que «el proceso social de decidir los objetivos de la convivencia y las formas de coordinarse para realizarlos se lleva a cabo en modo de interdependencia-asociación-coproducción/corresponsabilidad entre el gobierno y las organizaciones privadas y sociales» (Aguilar, 2007: 99). Buena gobernanza implica hacer todo ello garantizando el bien común, no solo mediante procesos democráticos y abiertos, sino también con resultados efectivos (Kaufmann et al., 2005). Esta amplitud del concepto hace que la elaboración de indicadores se convierta en un tema objeto de continuo debate. Desde una perspectiva macro podríamos decir que el concepto incluye elementos de buen gobierno (transparencia, rendición de cuentas, integridad), elementos de gobierno efectivo (liderazgo, calidad regulatoria, eficacia y eficiencia de la Administración), elementos de gobierno de la ley (Estado de derecho, imparcialidad y ausencia de corrupción) y elementos de gobierno democrático (elecciones libres y justas, estabilidad y ausencia de violencia). Por otra parte, podríamos conectar la buena gobernanza con una forma de gobierno en la que los bienes públicos son distribuidos con universalismo ético o, al menos, de forma no particularista (es decir, patrimonialista, clientelar o nepotista) (Mungiu Pippidi, 2010: 4). Unido todo, nuestro estudio atiende esencialmente a organizaciones de la sociedad civil que se centran en la denuncia de la corrupción y la promoción de elementos de buen gobierno en el Gobierno (sobre todo) y en las empresas (ver figura 1).

Finalmente, desde la teoría de los grupos de interés no podemos negar que las ONG que analizamos son grupos de interés, pues reúnen las tres condiciones esenciales para ello: son organizaciones reconocidas y reconocibles; defienden un interés identificado y definido por sus miembros, y buscan influir en el proceso político sin la intención de ejercer responsabilidades de gobierno (Medina y Muñoz, 2016: 25). Pero son grupos de interés con una advocacy clara a favor de la calidad democrática. La forma de entender mejor su funcionamiento es como un policy network, es decir, 
Figura 1.

Fines PRIORITARIOS PARA LAS ONG CONSUltadAS

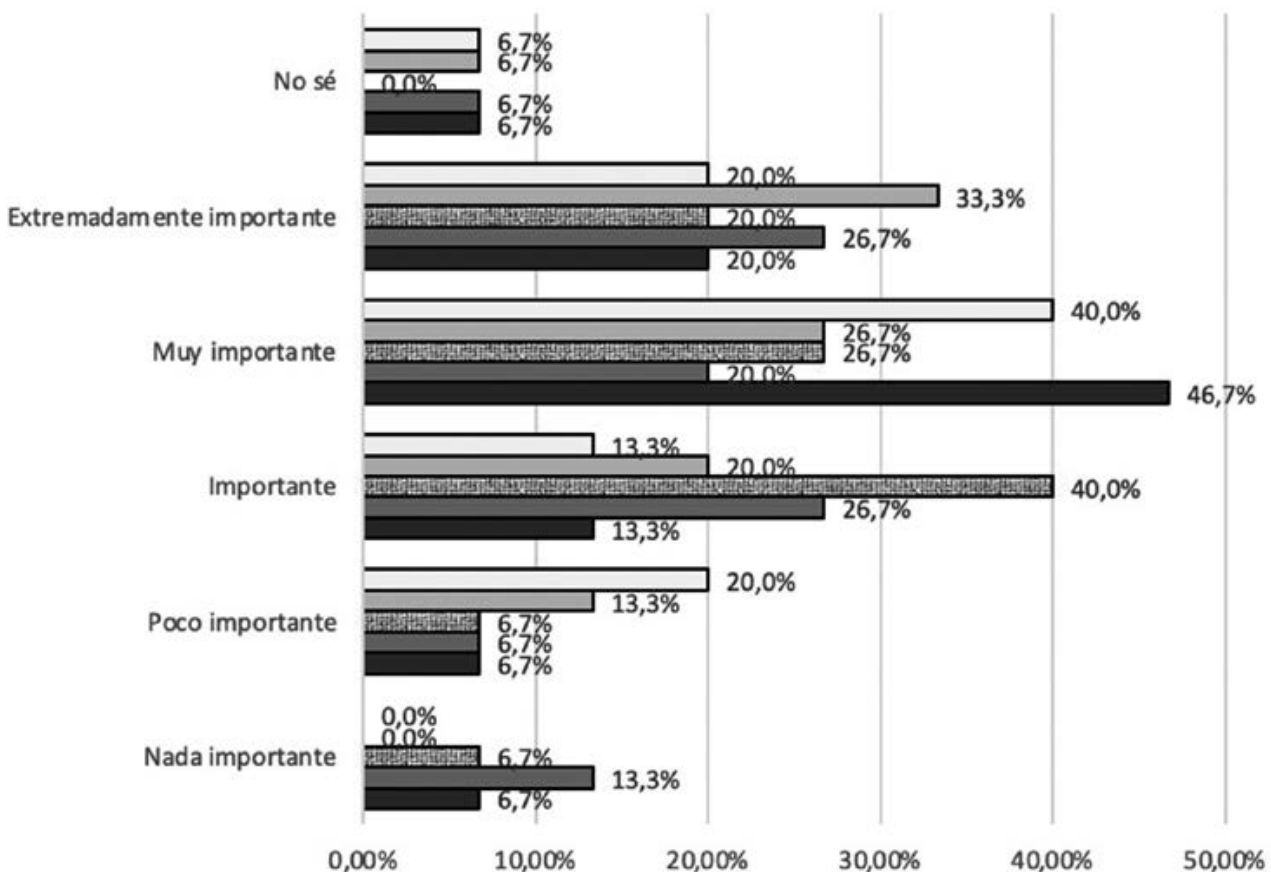

口 Lucha por una mejor rendición de cuentas financieras y económicas

口 Lucha por el derecho ciudadano a la información

घ Lucha contra la corrupción y la politización de la justicia mediante activid. preventivas

- Lucha contra corrupción del sector privado mediante prevención

- Lucha contra corrupción política nacional mediante actividades preventivas

Fuente: elaboración propia.

como «un conjunto de relaciones relativamente estables entre actores públicos y privados que interactúan a través de una estructura no jerárquica e interdependiente, para alcanzar objetivos comunes respecto a la política» (Chaqués, 2004: 36). En estas redes, la demanda esencial de las ONG radica en garantizarse un acceso sencillo a la interlocución con el Estado y en asegurar la concreción de compromisos mutuos a largo plazo a partir de objetivos determinados, todo ello en un contexto donde los cambios de Gobierno pueden generar alteración de interlocutores y prioridades. De ahí la importancia de mantener capacidad de denuncia, en caso de incumplimiento e, incluso, de saber generar cierto conflicto. Siguiendo la distinción de Grant (1989), podríamos decir que una gran parte de las ONG estudiadas buscan convertirse en insiders al subsistema de política, garantizándose un espacio formal de influencia y atesorando recursos útiles para los Gobiernos y mecanismos de represalia dañinos 
para la imagen de las organizaciones públicas (como el acceso fácil a los medios de comunicación).

En suma, creemos que las organizaciones seleccionadas se alinean adecuadamente con el marco teórico y, por ello, podemos analizar su labor como advocacy groups que desarrollan una labor de accontability social para combatir la corrupción y promover el buen gobierno, con un modelo de democracia cercana a las visiones deliberativas e inclusivas. Dicho esto, ¿podemos saber el impacto objetivo que las organizaciones seleccionadas han tenido y tienen en la mejora de la gobernanza en España en un periodo tan corto como el de la pandemia? Creemos que no. Una adecuada comprensión del fenómeno no puede obviar la complejidad del nuevo pluralismo, con gobiernos multinivel, economías globalizadas, redes sociales sin jerarquía y nuevos grupos antidemocráticos insertos en el sistema (García Guitián, 2016), por lo que conviene aclarar que nuestra visión será parcial y no garantizará la explicación de todas las variables intervinientes. En nuestro trabajo, lo que se analiza y mide es esencialmente la influencia en la agenda dedicada a la generación de instrumentos, procesos y órganos de buena gobernanza, sobre todo en aspectos de buen gobierno, que no es sino uno de los muchos componentes de la buena gobernanza.

Además, aunque el ámbito sea más modesto que el de medir la buena gobernanza en general, es obvio que conocer el impacto de campańas en un corto plazo es casi imposible. Los movimientos sociales que trabajan en la prevención y combate a la corrupción y, en consecuencia, promueven la transparencia, rendición de cuentas o integridad, tienen muy difícil conocer los impactos finales de su trabajo. También tienen difícil conseguir éxitos rotundos, dado que suelen cuestionar el statu quo (Schattchneider, 1960). El reto, por ello, es ser capaces de alinear medición con objetivos y estrategia, especialmente aquellos objetivos que la organización puede razonablemente controlar o influenciar suficientemente (Ebrahim, 2019). Cuando las organizaciones sociales pretenden ir más allá de lo razonable, el resultado tiende a ser el desperdicio de recursos y el falseamiento de sus propios datos. Los dirigentes de estas organizaciones pueden intentar usar un falso protagonismo en los cambios sociales profundos para obtener fondos y legitimarse, pero como una de las personas entrevistadas nos señaló: «Es un error que debe evitarse, generando respuestas realistas y basadas en la capacidad real de nuestro movimiento» (entrevista 3).

\section{EL MODELO PARA LA MEDICIÓN DEL ÉXITO}

Siguiendo a Ebrahim (2019), usaremos un modelo contingencial para analizar el rendimiento de las acciones de las ONG seleccionadas. En este modelo se distingue el rendimiento organizativo del rendimiento social. El rendimiento organizativo parte de un análisis de los inputs, las actividades y los productos finales. En el análisis de los inputs se pueden considerar como variables explicativas de los productos: a) los recursos económicos y de información de los que disponen las ONG; b) el acceso formal de estos grupos al proceso de elaboración de políticas públicas; c) las características del sector o 
colectivo al que representan y grado de concentración de la representación de intereses; d) la organización interna del grupo $(v$. g. grado en que las propuestas han sido elaboradas a partir del dialogo, discusión con los miembros del grupo al que representan); e) la internacionalización, que tiene en cuenta el grado en que los grupos colaboran con otros grupos de interés a nivel internacional para elaborar sus propuestas, y f) su capacidad tecnológica para el uso de datos. Las actividades serían las campañas, respecto de las cuales se puede comprobar qué se pretende alcanzar con ellas, su amplitud, su mayor o menor grado de confrontación y consenso, qué teoría del cambio conllevan (su lógica causal) y cómo se rendirá cuentas del trabajo realizado. Finalmente, se intentará comprobar qué productos se han generado de todo ello, bien sean reuniones con actores políticos relevantes, documentos, artículos en prensa y actividad en redes sociales, etc.

El rendimiento social se podría dividir en impacto a corto plazo y a largo. A corto plazo, podría ser el cambio de actitud o decisión del Gobierno, la aceptación de propuestas o la redacción de normas nuevas; a largo plazo el impacto tendría que ser la reducción de la corrupción o la mejora en la integridad del Gobierno. Ciertamente, estos últimos impactos tienen enormes dificultades de medición por dos razones. La primera es el insuficiente conocimiento de las relaciones de causa-efecto. La segunda tiene que ver con el tiempo necesario para observar los resultados finales. Por estas razones, el impacto que se podría medir en este estudio es el relacionado con la aceptación de propuestas y la influencia alcanzada en las decisiones o no decisiones tomadas por los Gobiernos.

Desde una perspectiva teórica, nos unimos a una línea de explicación de los éxitos o fracasos basada en la eficacia estratégica de las elecciones tácticas y operacionales; en última instancia, en la habilidad de los actores para trabajar por el cambio en entornos complejos y cambiantes (Ackerman y Kruegler, 1994) y no tanto en determinantes estructurales (Tarrow, 1998). Es cierto que las elecciones de los actores sociales están constreñidas por el entorno en el que se sitúan: ciertos entornos favorecen más que otros el éxito de la movilización, pero no determinan el éxito o fracaso. Otra teoría con la que tampoco nos identificamos es la de la movilización de recursos (Weinstein 2007). Los recursos importan, pero partiendo de unos recursos financieros básicos e ineludibles, la dinámica de la acción de los actores sigue siendo clave, su resiliencia (Bob y Nepstad, 2007), sus estrategias y tácticas, la información y experiencia que poseen (Klüger, 2012) y su capacidad de liderazgo explican más que los factores financieros el impacto. Diferentes estudios nos muestran que las personas que ejercen de líderes sociales desarrollan tres papeles distintos en sus campañas por el cambio social. Son agitadoras, innovadoras y organizadoras. Quienes agitan son capaces de hacer llegar a la conciencia social los problemas que la gente sufre o percibe. Quienes innovan crean soluciones posibles para los problemas. Y quienes organizan son capaces de coordinar acciones entre los diferentes grupos, organizaciones y sectores para generar la escalada que permita la adopción de la decisión propuesta. Todo proceso de cambio necesita los tres roles para el éxito. La agitación sin innovación genera quejas sin solución y, con ello, frustración; la innovación sin organización implica ideas sin impacto (Battilana y Kimsey, 2017: 2). 
Insistiendo en esta idea de la importancia de la capacidad estratégica como factor contingencial clave, es necesario distinguir campañas tácticas de campañas estratégicas. Las campañas reactivas y puramente tácticas no suelen aportar rendimiento social y agotan su éxito en el rendimiento organizativo. Los datos indican que estas campañas tienen poca repercusión social: se observan numerosos casos de capturas políticas de las campañas y de los activistas, y aunque algunas intervenciones consiguen incorporar reformas, suelen ser mero window-dressing que nunca se implementa finalmente (Mungiu Pippidi, 2010). Frente a ello, las intervenciones estratégicas se caracterizan por: a) usar diversas y coordinadas tácticas que tratan de trabajar sobre los diversos componentes de la escala causal de forma innovadora; b) propulsar la generación pública de información que tiene objetivos claros y estratégicos, no la mera agregación de datos y documentos; c) buscar interlocución con los Gobiernos y no mera agregación de voces; d) habilitar entornos para la acción colectiva, reduciendo el miedo a la represalia y la captura; e) promocionar la capacidad de los órganos estatales, sobre todo los dedicados a la accountability horizontal, para incentivar conductas íntegras y sancionar las conductas abusivas o corruptas; f) reconocer la interdependencia de los tres niveles de accountability; g) fortalecer la cooperación y la integración vertical de las organizaciones para acudir con una estrategia común a los procesos de negociación nacional, dado que son los de mayor impacto; h) capturar una visión de conjunto de los procesos de gobierno para ejercer presión sobre los puntos estratégicos, e i) seguir una estrategia de sándwich, en la que se busca envolver a los actores enemigos de la buena gobernanza bajo la acción combinada de las organizaciones de la sociedad civil y los reformistas presentes en la estructura estatal, gracias a una interlocución eficaz producto de la confianza mutua (Fox, 2015: 352 y ss.).

Siguiendo este modelo contingencial, vamos a ver si las organizaciones seleccionadas consideran que este modelo de éxito, centrado en la capacidad estratégica y relacional, es el adecuado o no. Después, analizaremos las campañas, para mayor concreción y detalle. Empezaremos analizando los inputs que tienen importancia estratégica y relacional a efectos de comprobar si están debidamente incorporados internamente. En primer lugar, existe una amplia presencia en redes sociales, lo cual garantiza difusión de ideas y contenidos, todas tienen su propia página web y dos de cada tres consideran que el uso de las nuevas tecnologías supone un factor importante para su labor (tabla 2). Con esto se demuestra la importancia del uso de tácticas diversas para propulsar información.

TABLA 2.

REDES SOCIALES Y TECNOLOGÍA

\begin{tabular}{cccc}
\hline \multirow{2}{*}{$\begin{array}{c}\text { ¿En qué redes sociales tiene presencia } \\
\text { su organización? }\end{array}$} & \multicolumn{2}{c}{$\begin{array}{c}\text { ¿Cómo de importante es la promoción } \\
\text { de la innovación tecnológica aplicada } \\
\text { para un mejor gobierno? }\end{array}$} \\
\hline Twitter & $93,3 \%$ & Nada importante & $20,0 \%$ \\
\hline Facebook & $100 \%$ & Poco importante & $13,3 \%$ \\
\hline
\end{tabular}


$\ldots / \ldots$

¿En qué redes sociales tiene presencia su organización?

¿Cómo de importante es la promoción de la innovación tecnológica aplicada para un mejor gobierno?

\begin{tabular}{|c|c|c|c|}
\hline Linkedin & $80,0 \%$ & Importante & $40,0 \%$ \\
\hline Youtube & $73,3 \%$ & Muy importante & $26,7 \%$ \\
\hline Instagram & $40,0 \%$ & & \\
\hline
\end{tabular}

Fuente: elaboración propia.

Los recursos disponibles (tablas 3 y 4) para realizar su labor es otro de los aspectos importantes para entender su capacidad de actuación, aun cuando, a partir de unos mínimos, no por tener más recursos se garantiza más éxito. De hecho, una de las interlocutoras nos indicó: "Cuando tuvimos la millonaria ayuda de $\mathrm{X}$ nos enredamos con problemas de gestión del personal y perdimos iniciativa» (entrevista 5). En general, las organizaciones disponen de unos recursos humanos pequeños, pero altamente capacitados; económicamente, más de la mitad no se sostienen solo con las cuotas de sus miembros. Esto nos plantea el problema de la dependencia pública y la captura de fondos oficiales. Sin embargo, como se ve en las encuestas, entrevistas y datos de sus presupuestos, la presencia de fondos públicos es baja y tiende a ser evitada en la medida de lo posible, sobre todo los fondos finalistas. No obstante, es importante separar de los fondos públicos los provenientes de la Unión Europea, pues son fondos precisamente creados para fortalecer la labor de control del poder político nacional o local y, por ello, bienvenidos y sin previsibles riesgos de captura, según los entrevistados (entrevistas 1, 2, 4, 5 y 8). Nuevamente se demuestra una coherencia entre estructura y fines, pues solo desde una independencia financiera y con recursos humanos capacitados es posible desarrollar actividades estratégicas.

TABLA 3.

Recursos humanos

\begin{tabular}{lclc}
\hline \multicolumn{1}{c}{$\begin{array}{c}\text { Tenemos recursos humanos } \\
\text { (sean profesionales o voluntarios) } \\
\text { suficientes para realizar nuestra labor }\end{array}$} & \multicolumn{2}{c}{$\begin{array}{c}\text { Una parte mayoritaria (más del 50 \%) } \\
\text { de nuestros recursos humanos } \\
\text { son profesionales muy bien formados } \\
\text { y entrenados para esta labor }\end{array}$} \\
\hline Totalmente en desacuerdo & $6,7 \%$ & Totalmente en desacuerdo & $0 \%$ \\
\hline En desacuerdo & $33,3 \%$ & En desacuerdo & $0 \%$ \\
\hline Ni de acuerdo ni en desacuerdo & $26,7 \%$ & Ni de acuerdo ni en desacuerdo & $6,7 \%$ \\
\hline De acuerdo & $33,3 \%$ & De acuerdo & $13,3 \%$ \\
\hline Totalmente de acuerdo & $0 \%$ & Totalmente de acuerdo & $73,3 \%$ \\
\hline No sabe/No contesta & $0 \%$ & No sabe/No contesta & $6,7 \%$ \\
\hline
\end{tabular}

Fuente: elaboración propia. 

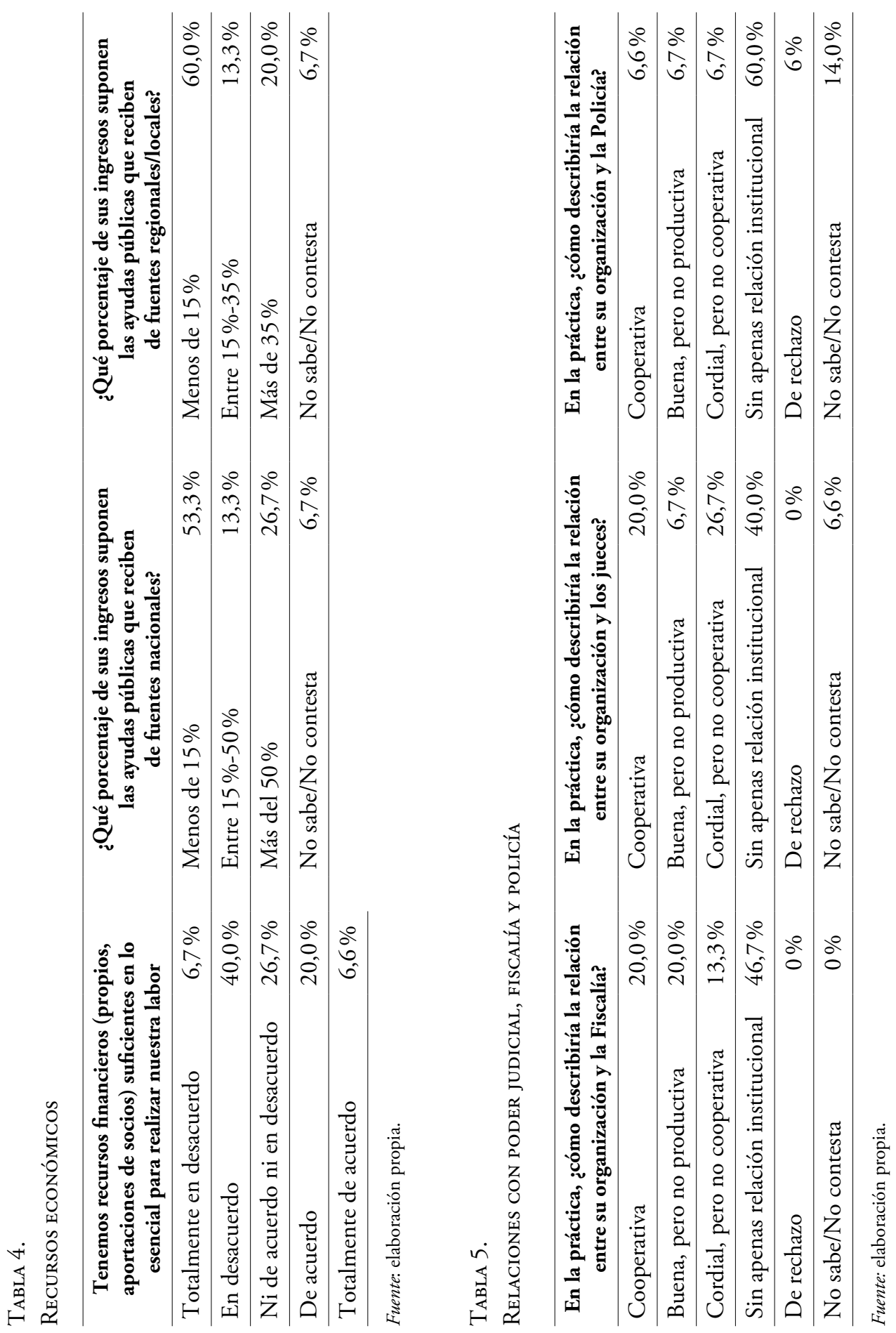
La capacidad relacional de las organizaciones seleccionadas se ha medido por su percepción de la calidad de las relaciones con los poderes y organismos públicos dedicados a la prevención y lucha contra la corrupción (tabla 5), así como con partidos y Gobiernos (tabla 6), y también por su grado de cooperación entre ellas y de su internacionalización (tabla 7). Del análisis de los resultados se desprende que las buenas relaciones, la cordialidad e, incluso, la cooperación (un tercio así lo considera en sus relaciones con partidos y Gobierno) son mayoritarias. Este dato es muy importante, pues las estrategias sándwich y la suma de accountabilities tienden a producir éxitos más duraderos, como ya vimos. En las entrevistas esta idea se ha repetido: «Es importante apoyar a la Fiscalía para que cumpla con su misión» (entrevista 3); «la cooperación con la gente honesta de los partidos es una obligación que tenemos» (entrevista 1); «ha sido preciso colaborar con la Dirección de Gobernanza Pública para conseguir un Plan de Gobierno Abierto ambicioso» (entrevista 7).

TABLA 6.

RELACIONES CON PARTIDOS Y GOBIERNO

\begin{tabular}{lclc}
\hline $\begin{array}{c}\text { En la práctica, ¿cómo describiría la relación } \\
\text { entre su organización y los partidos políticos } \\
\text { con representación parlamentaria? }\end{array}$ & $\begin{array}{c}\text { En la práctica, ¿cómo describiría la relación } \\
\text { entre su organización y los miembros } \\
\text { del Gobierno? }\end{array}$ \\
\hline Cooperativa & $33,3 \%$ & Cooperativa & $33,3 \%$ \\
\hline Buena, pero no productiva & $26,7 \%$ & Buena, pero no productiva & $6,7 \%$ \\
\hline Cordial, pero no cooperativa & $13,3 \%$ & Cordial, pero no cooperativa & $13,3 \%$ \\
\hline Sin apenas relación institucional & $20,0 \%$ & Sin apenas relación institucional & $33,3 \%$ \\
\hline De rechazo & $0 \%$ & De rechazo & $6,7 \%$ \\
\hline No sabe/No contesta & $6,7 \%$ & No sabe/No contesta & $6,7 \%$ \\
\hline
\end{tabular}

Fuente: elaboración propia.

TABLA 7.

INTERNACIONALIZACIÓN Y COOPERACIÓN

Formamos parte de una organización internacional o de redes internacionales de lucha contra la corrupción
Colaboramos con otras organizaciones de nuestro entorno

\begin{tabular}{|c|c|c|c|}
\hline Sí & $46,70 \%$ & Sí & $100,00 \%$ \\
\hline No & $40,00 \%$ & & \\
\hline No sabe/No contesta & $13,30 \%$ & & \\
\hline
\end{tabular}

Fuente: elaboración propia.

Finalmente, antes de entrar en las campañas, es importante conocer qué es lo que los propios actores consideran éxito en su trabajo. Como se verá, muy mayoritariamente, el éxito no se relaciona con actividades tácticas y de confrontación, sino con la generación de influencia y conocimiento, en definitiva, con actividades estratégicas y no con campañas de corto impacto mediático (tabla 8). 
TABLA 8.

¿QUÉ ES ÉXITO?

¿Cuáles serían las actividades que, a su juicio, han constituido su mayor éxito en estos ańos? Respuesta múltiple, hasta 3

\begin{tabular}{|c|c|}
\hline Sacar a luz el problema & $40,0 \%$ \\
\hline Contribuir a que vayan a la cárcel corruptos & $6,7 \%$ \\
\hline $\begin{array}{l}\text { Contribuir a la aprobación de leyes } \\
\text { importantes de prevención o lucha contra la } \\
\text { corrupción }\end{array}$ & $46,7 \%$ \\
\hline $\begin{array}{l}\text { Innovar en los instrumentos de detección e } \\
\text { investigación de corrupción }\end{array}$ & $20,0 \%$ \\
\hline Ganar influencia y ser escuchados & $73,3 \%$ \\
\hline Parar actividades corruptas que detectamos & $6,7 \%$ \\
\hline $\begin{array}{l}\text { Generar conocimiento sobre el fenómeno } \\
\text { (informes, manuales prácticos...) }\end{array}$ & $86,7 \%$ \\
\hline Otras (indique cuáles) & $\begin{array}{l}26,7 \% \\
\text { a) Concienciar sobre la importancia del } \\
\text { Estado de derecho. } \\
\text { b) IV Plan de Acción OGP de España. } \\
\text { c) Profesionalizar la función de compliance } \\
\text { en Espańa. } \\
\text { d) Personarnos en las causas como acusación } \\
\text { popular. }\end{array}$ \\
\hline
\end{tabular}

Fuente: elaboración propia.

\section{LAS CAMPAÑAS}

La denuncia de la "suspensión del derecho de acceso" y la promoción de la transparencia

Como consecuencia de la pandemia derivada de la COVID-19, el Gobierno decretó el estado de alarma. Mediante la disposición adicional tercera del Real Decreto 463/2020, de 14 de marzo, por el que se declara el estado de alarma para la gestión de la situación de crisis sanitaria, el Ejecutivo tomó la decisión de suspender «los plazos para la tramitación de los procedimientos de las entidades del sector público» hasta que el Real Decreto o sus prórrogas carecieran de vigencia. Esto implicaba que los procesos de acceso a la información ya abiertos quedaban en suspenso. Pero en el punto cuarto de dicho apartado se establecía que las cuestiones referidas «a situaciones estrechamente vinculadas» con el coronavirus podían abrir nuevos procedimientos de acceso y se responderían dentro de los plazos establecidos. Sin embargo, el nuevo Decreto 465/2020, de 17 de marzo cambió la regulación y permitió al Gobierno usar la discrecionalidad para decidir si contestaba o no dicho tipo de demandas de acceso. 
Ante esta situación, que se unía a cifras oficiales sobre la pandemia confusas, ruedas de prensa con preguntas previamente seleccionadas sin publicidad y retrasos en publicar los contratos de emergencia en el Portal de Transparencia de la Administración General del Estado, la opción de las ONG de la Coalición Proacceso fue lanzar una campaña para denunciar el hecho y exigir la reapertura de plazos para el derecho de acceso, especialmente de aquellas peticiones relacionadas con la COVID-19. También se pedía documentar debidamente todos los procesos de toma de decisiones realizados durante la pandemia para permitir la trazabilidad y la disponibilidad de la información para la ciudadanía, así como reforzar la transparencia de las contrataciones públicas realizadas en situación de emergencia. Además, se solicitaba un portal que centralizara toda la información a nivel nacional, regional y local de la forma más específica posible (González León, 2021: 25). La campaña se lanzó en redes sociales, pero también contó con la participación de los principales medios de comunicación escritos.

Hasta aquí podríamos considerar que se trataba de una campaña táctica que respondía a un hecho puntual y que tendría como fin el cambio de decisión por parte del Gobierno, modificando el Decreto de 17 de marzo; este hecho, sin embargo, no se logró hasta el 1 de junio y por otras razones distintas a la presión de las ONG. Conforme a la teoría que mantiene este artículo, las ONG fueron conscientes de la insuficiencia de esta denuncia puntual para cambiar las tendencias de fondo. Por ello, optaron por aprovechar estas medidas gubernamentales para generar toda una llamada de atención sobre el problema de la regulación e implementación de la transparencia en la actividad pública, en un momento en el que la ciudadanía buscaba ansiosa información y empezaba a usar con más energía su derecho; de hecho, el año 2020 había sido el año con más solicitudes de acceso desde la aprobación de la ley de transparencia a finales de 2013 (figura 2). Un aspecto estratégicamente importante era apoyar al Consejo de Transparencia en su labor. Este órgano tenía personas, desde su inicio, profundamente implicadas en la promoción de la transparencia, pero no se le dejaba cumplir plenamente su misión. Así, mientras que el crecimiento de la plantilla entre 2015 y 2020 fue de un $15 \%$, el aumento de la carga de trabajo, solo en reclamaciones, se situaba en un $219 \%$, a lo que habría que añadir, por ejemplo, un aumento de las solicitudes de información de los ciudadanos del $460 \%$. Los recursos asignados al Consejo no son suficientes ni siquiera para el mantenimiento de sus actividades; en concreto, el presupuesto ha ido disminuyendo hasta 2021, año en que se ha incrementado muy débilmente.

Según Access Info Europe, en los últimos años, además, se ha producido una clara tendencia de incumplimiento de las decisiones del Consejo por parte de los organismos de la Administración central, pasando de un $88 \%$ de cumplimiento en 2015 a solo un $60 \%$ de decisiones cumplidas en 2020. Más aún, el Gobierno ha iniciado cada vez más litigios contra las decisiones del Consejo, con 28 demandas en 2020. Con esto en mente, garantizado el apoyo de la prensa y la de algunos miembros relevantes de los principales partidos, era el momento de usar la «ventana de oportunidad» (Kingdon, 2010) por la coalición promotora y quebrar el equilibrio puntuado (Sabatier 1998; Baumgartner y Jones, 1993): «Sabíamos que con el confinamiento la gente 
sería más sensible a nuestras reclamaciones y que podíamos conectar los problemas de opacidad con las acusaciones de autoritarismo, era un buen momento y teníamos apoyo en la prensa» (entrevista 3). Con todo esto en mente, la coalición reclamó una reforma urgente de la ley de transparencia para garantizar la verdadera independencia del Consejo de Transparencia. También se pidió que sus decisiones fueran vinculantes y que se dotase al órgano de facultades de inspección y sanción. Este intento de horizontalización es clave para entender la estrategia, validando el aprendizaje colectivo de las $\mathrm{ONG}$ en el uso de las campañas.

\section{Figura 2.}

Evolución MENSUAL DE PETICIONES DE ACCESO EN LA AGE

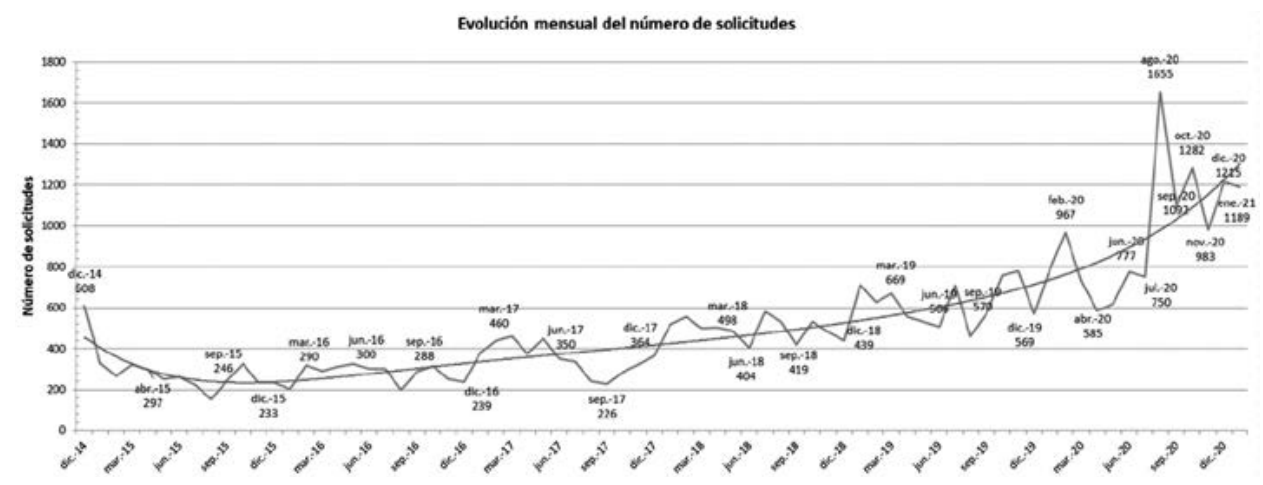

Fuente: Portal de Transparencia de la AGE.

TABLA 9.

MarCo DE ANÁLISIS

\begin{tabular}{ccc}
\hline $\begin{array}{c}\text { Campańa 1: suspensión del } \\
\text { derecho de acceso }\end{array}$ & Resultados organizativos & Resultados sociales \\
\hline $\begin{array}{c}\text { Intervención: inicialmente } \\
\text { táctica y de confrontación, } \\
\text { pero con visión estratégica, } \\
\text { buscando fortalecer la } \\
\text { accountabilty horizontal. }\end{array}$ & $\begin{array}{c}\text { Denuncia en redes sociales; } \\
\text { declaraciones en prensa; } \\
\text { documentos con datos; } \\
\text { comunicación virtual con } \\
\text { actores políticos relevantes. }\end{array}$ & $\begin{array}{c}\text { Cambio de actitud del } \\
\text { Gobierno; activación de } \\
\text { nombramientos largamente } \\
\text { parados; la aceptación de } \\
\text { propuestas de renovación de } \\
\text { la ley de transparencia. }\end{array}$ \\
\hline
\end{tabular}

Fuente: elaboración propia.

Como resume la tabla 9, algunos efectos (indirectos) de esta campaña, de acuerdo a los entrevistados, fueron la «aceleración" (entrevista 4) en el nombramiento del presidente del Consejo de Transparencia, que estaba vacante desde 2017; también, el 29 de diciembre de 2020, el Ministerio de Sanidad hizo públicos los nombres de los quince técnicos que formaban parte del comité encargado de evaluar los cambios de fase de 
cierre en la desescalada de la crisis de COVID-19. De forma más directa, el Gobierno publicó en abril en el Portal de Transparencia una nota informativa indicando que las solicitudes se estaban tramitando y que solo se había suspendido la notificación de la resolución estimatoria o desestimatoria, y sendos informes de la Abogacía del Estado en los que se concluía que, caso a caso, aquellas solicitudes de acceso a la información pública y las reclamaciones ante el Consejo de Transparencia y Buen Gobierno que tuvieran relación con los hechos justificativos de la declaración del estado de alarma o fueran de interés general se podían seguir tramitando (ver Blanes, 2021: 18). En conjunto, se consiguió una actitud más proactiva del Gobierno para fortalecer la transparencia.

\section{El IV Plan de Gobierno Abierto: el enfoque colaborativo}

España es miembro de la Alianza por el Gobierno Abierto (OGP) desde abril de 2011. Cada dos años, los 78 países miembros proceden a elaborar su plan de acción que es implementado en dicho periodo y, posteriormente, sometido a evaluación por el Independent Reporting Mechanism (IRM) para conocer el avance y grado de cumplimiento de los compromisos. Desde que España entró en la OGP, se han desarrollado tres planes de acción de gobierno abierto, el último finalizó en $2019^{3}$. Ninguno de los dos primeros planes se diseńó contando con la sociedad civil, lo cual constituía una debilidad importante. Con estos antecedentes, la recién creada (en 2016) Dirección General de Gobernanza Pública (DGGP), encargada de diseñar el III Plan Nacional, abrió un proceso participativo que se desarrolló durante el primer semestre de 2017. La forma de hacerlo fue doble (ver Alvira, 2019): por una parte, generando un espacio de consulta abierta habilitado en el Portal de Transparencia de la Administración General del Estado. Por otra, conectando directamente con representantes de la sociedad civil. Como consecuencia de ello, se recibió un amplio conjunto de propuestas que fueron analizadas en abril de 2017, aprobándose el borrador del plan el 12 de mayo. Posteriormente, entre el 12 y el 26 de mayo de 2017 se abrió un nuevo periodo de consulta pública. En junio de 2017 fue aprobado el texto definitivo del III Plan de Acción de Gobierno Abierto de España 2017-2019. Este modelo de participación en el diseño del plan fue criticado por las ONG participantes y por otras que no habían sido convocadas a participar (entrevistas $1,4,6,8$ ). La campaña que se inició fue la de proponer la creación de algún foro permanente que permitiera que futuros diseños del plan tuvieran una verdadera participación de la sociedad civil: «Nuestros contactos en Washington en el IRM nos señalaron que esta era la vía correcta para consolidar la participación, porque la OGP defendía la creación de un multi-stakeholder forum (MSF) en cada país para la elaboración del plan, siguiendo los estándares de participación y cocreación de la Alianza» (entrevista 8).

3. Hoy en día también hay 56 socios subnacionales del OGP, de ellos 4 españoles: Aragón, Cataluña, Euskadi y la ciudad de Madrid. 
Esta idea del foro permanente fue inmediatamente acogida por la DGGP, y el 20 de febrero de 2018 se publicó en el Boletín Oficial del Estado la Orden HFP/134/2018, de 15 de febrero, por la que se crea el Foro de Gobierno Abierto, con la finalidad de institucionalizar la colaboración y fortalecer el diálogo permanente entre las Administraciones públicas y la sociedad civil. El Foro, siguiendo las recomendaciones de la OGP, tiene composición paritaria y está compuesto por el presidente y 64 vocales, de los cuales 32 lo son en representación de las Administraciones públicas y 32 en representación de la sociedad civil. Este espacio de encuentro y diálogo permanente funciona en Pleno, en Comisión Permanente y en grupos de trabajo, con el mismo número de representantes de las Administraciones públicas y de la sociedad civil: «Estuvimos hablándolo y teníamos claro que no podíamos quedarnos fuera porque era la forma de propulsar propuestas clave» (entrevista 1); «teníamos miedo a la captura, pero viendo la actitud del Ministerio se nos fue diluyendo» (entrevista 7).

Ha sido precisamente el Foro, a través de sus grupos de trabajo y de su Comisión Permanente, previa apertura de un periodo de recepción de propuestas en 2019, el que ha establecido las prioridades de reforma para el IV Plan, identificando los principales problemas y objetivos. Todo ello en un periodo marcado por las sucesivas elecciones generales y, más tarde, por la pandemia. El 8 de junio de 2020 se aprobó, en reunión de la Comisión Permanente del foro, el nuevo calendario de la hoja de ruta para el IV Plan y se aprobó la propuesta de composición, calendario y dinámica de los talleres deliberativos, integrados por las Administraciones y la sociedad civil, cuya misión ha sido debatir y priorizar las ciento treinta propuestas que la ciudadanía y las organizaciones sociales formularon en el proceso de consulta previa. El primer taller, relativo a sensibilización, tuvo lugar el día 12 de junio 2020 y en él se abordó el debate y priorización, de acuerdo con los criterios establecidos en el Documento Marco, de las dieciocho propuestas que, en esta área del interés social, formuló la ciudadanía en el proceso participativo de consulta previa. El segundo taller se celebró el 16 de junio y sus integrantes debatieron las sesenta y una propuestas ciudadanas relativas al reforzamiento y mejora de la transparencia en las Administraciones públicas. El tercer taller, desarrollado el 17 de junio, centró la deliberación en el análisis, valoración y priorización de las treinta aportaciones ciudadanas recabadas en la consulta previa, en materia de formación y sensibilización. Finalmente, el cuarto y último taller se realizó el 19 de junio y versó sobre las veinticuatro propuestas sobre integridad pública que fueron debatidas y priorizadas por todas las personas participantes.

Posteriormente, se convocaron tres talleres deliberativos adicionales con la finalidad de que las Administraciones públicas presentaran a las organizaciones de la sociedad civil sus propuestas de compromisos para dar satisfacción a las demandas ciudadanas, conforme a las prioridades establecidas en los talleres celebrados en junio, de modo que estas propuestas pudieran ser asimismo debatidas (Gobierno de España, 2020). El resultado de todo ello es un plan a cuatro años (2020-2024), con diez compromisos en torno a cuatro grandes objetivos: a) transparencia y rendición de cuentas; b) participación; c) integridad, y d) sensibilización y formación. Se incluye, además, un quinto bloque en el que se incorporan iniciativas de las comunidades y 
ciudades autónomas y de las entidades locales. Todas las propuestas y compromisos surgen de las demandas de la sociedad civil y han sido validadas por esta (ver págs. 35-38 del IV Plan). Como dicen nuestros entrevistados, «la clave va a estar en mantenernos vigilantes y exigentes, que no nos capturen con buenas formas, hay que denunciar siempre los incumplimientos» (entrevista 5); «tenemos que trabajar con los que tienen mejor voluntad y ayudar; si conseguimos fortalecerlos serán nuestros aliados» (entrevista 8). La tabla 11 resume los elementos principales de esta campaña.

TABLA 11.

MarCo de ANÁLISIS

\begin{tabular}{|c|c|c|}
\hline $\begin{array}{c}\text { Campańa 3: Foro de Gobierno } \\
\text { Abierto }\end{array}$ & Resultados organizativos & Resultados sociales \\
\hline $\begin{array}{l}\text { Intervención: claramente estratégica, } \\
\text { buscando «el efecto sándwich», se } \\
\text { trata de trabajar sobre los diversos } \\
\text { componentes de la escala causal y de } \\
\text { promocionar la capacidad de los } \\
\text { órganos estatales dedicados a la } \\
\text { accountability, se busca fortalecer la } \\
\text { cooperación y la integración vertical } \\
\text { de las organizaciones para acudir } \\
\text { con una estrategia común a los } \\
\text { procesos de negociación nacional, } \\
\text { dado que son los de mayor impacto. }\end{array}$ & $\begin{array}{c}\text { Reuniones virtuales con } \\
\text { otras ONG. Participación } \\
\text { en talleres. Elaboración y } \\
\text { debate de propuestas. } \\
\text { Elaboración de } \\
\text { documentos. Reuniones } \\
\text { virtuales con } \\
\text { representantes de órganos } \\
\text { de accountability } \\
\text { horizontal. Comunicados } \\
\text { de prensa. Advocacy. }\end{array}$ & $\begin{array}{l}\text { Corto plazo: creación del } \\
\text { foro. Aceptación de } \\
\text { propuestas. Mecanismos } \\
\text { de seguimiento. } \\
\text { Largo plazo: mejora de la } \\
\text { buena gobernanza. }\end{array}$ \\
\hline
\end{tabular}

Fuente: elaboración propia.

En paralelo a la generación del IV Plan, un conjunto de ONG han desarrollado campañas para la trasposición de la Directiva (UE) 2019/1937 sobre protección a las personas que informen sobre infracciones del Derecho de la Unión. Una directiva en la que la presión de las ONG internacionales más importantes en este ámbito ha tenido un papel central en su nacimiento y desarrollo. Esta trasposición se ha incorporado como compromiso al IV plan de GA, pero ello no ha evitado una amplia movilización previa de las ONG para que la trasposición recogiera todos los elementos esenciales de una adecuada protección. En torno a Corruptil/Blue Print, por una parte, y a XNet, por otra, se han desarrollado dos campañas diferentes. La primera, en la que están presentes algunas whistleblowers relevantes, con ayuda técnica de la Agencia Anti Frau de Valencia y de Blue Print, se ha centrado en elaborar directamente una propuesta de ley que trataba ante todo de garantizar la independencia del órgano nacional de recepción de denuncias y protección a los alertadores. Esa propuesta se presentó a todas las fuerzas parlamentarias para que la incluyeran como propia en su agenda de proposiciones. La segunda se centró, ante todo, en aclarar los aspectos técnicos de la norma y en poner a disposición de las organizaciones públicas y privadas un modelo de buzón que garantiza la anonimidad, sin por ello perder la capacidad de interlocución con el 
alertador/a. En junio de 2020 se ha creado un grupo de trabajo de la Sección de Derecho Público de la Comisión General de Codificación, encargado de preparar la propuesta de texto articulado. Esta Comisión abrió un periodo de consulta pública de conformidad con lo previsto en el artículo 133 de la Ley 39/2015, de 1 de octubre, del Procedimiento Administrativo, en enero de 2021. Antes, tuvo una reunión virtual con representantes de ONG dedicadas a la promoción del buen gobierno: «No nos dieron la oportunidad de estar dentro de la Comisión, pero no vamos a dejar que la ley no reúna las condiciones esenciales de protección» (entrevista 2 ).

\section{CONCLUSIONES}

Basándonos en una encuesta a las organizaciones seleccionadas y en entrevistas en profundidad y desk review, se ha podido comprobar cómo, desde la narración propia de las organizaciones, se configura una idea de los fines, medios y resultados apropiados a su labor que es muy parecida a la que la literatura y diferentes metaevaluaciones considera como válidos para este tipo de policy networks. Partiendo de la visión propia de los sujetos de estudio, se han analizado dos campañas desarrolladas durante la pandemia. Esta investigación muestra, en el primer caso estudiado, que la labor de control social tiene más éxito cuando conecta con problemas que son percibidos como importantes por la gente, haciendo aflorar un interés latente (Truman, 1951); ahora bien, como quiera que el interés muta muy rápido, es preciso tener estrategias a medio y largo plazo para evitar caer en la irrelevancia. En las dos campañas estudiadas se ha podido comprobar, efectivamente, la importancia que las ONG en este ámbito dan a un enfoque estratégico frente a la mera confrontación puntual (Fox, 2015). También se ha podido comprobar la importancia de la provisión de información y generación de conocimiento como factor de éxito (Klüver, 2012). Así, de los casos estudiados se desprende que las organizaciones consideran el éxito como algo vinculado a la influencia, la participación y la generación de conocimiento sobre los temas. De acuerdo con diversos estudios de caso sobre el papel de los advocacy groups en la rendición de cuentas social, esta tiene más éxito y promueve cambio real cuando: explora vías para trabajar con actores prorreforma insertos en el Estado; privilegia la generación de incentivos en lugar de presionar a los políticos y burócratas; promociona la construcción de eficacia en las organizaciones de accountability horizontal; busca la creación de alianzas y redes estratégicas en lugar de relaciones individuales, y se inserta en los sistemas de accountability existentes, reforzándolos (O'Meally, 2013). Nuevamente, los casos muestran la importancia que para las organizaciones tiene trabajar en coalición interna y con los actores públicos dedicados a labores de accountability horizontal y de control interno del propio Gobierno, el fortalecimiento de las instituciones de control, la construcción de redes estratégicas o la inserción en sistemas previos de accountability, como los planes de gobierno abierto.

En suma, este artículo contribuye a conocer y definir, para España, una parte de lo que García Guitián denomina el «mapa de representación y participación» (2016: 81), 
y lo hace de forma coherente con un modelo normativo de democracia y sociedad civil que asume la complejidad y fomenta la deliberación y cooperación entre redes de actores y organizaciones vinculadas a la búsqueda de un mejor gobierno. La limitación esencial conecta con el corto espacio temporal estudiado y la concentración en unas pocas organizaciones, aunque sean las más importantes en este ámbito. En estudios posteriores se deberían analizar más en profundidad los procesos de coalition building y de negociación, así como los elementos más informales de las relaciones de poder e influencia. Por ejemplo, es cierto que los grupos de interés dirigen esencialmente su influencia hacia sus amigos (Baumgartner y Leech, 1998); esto conecta probablemente con un rasgo de nuestro sistema social —el amiguismo — que ha caracterizado el modelo de relaciones de los grupos de interés en España. Un amiguismo ya estudiado por Linz y Molins y que habría que estudiar en la realidad presente (Molins, 2016). En todo caso, esta investigación ha generado un modelo de análisis que podrá ser replicado en estudios posteriores para generar códigos, conceptos y teorías cada vez más sólidas.

\section{Referencias}

Ackerman, Peter y Chris Kruegler. 1994. Strategic nonviolent conflict: The dynamics of people power in the twentieth century. Westport, Conn.: Praeger.

Aguilar, Luis Fernando. 2007. Gobernanza y gestión pública. Ciudad de México: Fondo de Cultura Económica.

Alvira, Francisco (coord.). 2019. Evaluación de la participación pública en el III Plan de Acción de Gobierno Abierto de España. Madrid: INAP.

Baldwin, David A. 2000. «Success and failure in foreign policy», Annual Review of Political Science, 3: 167-182. Disponible en: https://doi.org/10.1146/annurev. polisci.3.1.167.

Battilana, Julie y Marissa Kimsey. 2017. «Should You Agitate, Innovate, or Orchestrate?», Stanford Social Innovation Review [website], 18-09-2017. Disponible en: https://ssir.org/articles/entry/should_you_agitate_innovate_or_orchestrate.

Baumgartner, Frank R. y Bryan D. Jones. 1993. Agendas and Instability in American Politics. Chicago: Chicago University Press.

Baumgartner, Frank R. y Beth Leech. 1998. Basic Interests: The Importance of Groups in Politics and in Political Science. Princeton: Princeton University Press. Disponible en: https://doi.org/10.1515/9781400822485.

Blanes, Miguel Ángel. 2021. "La incidencia del COVID-19 sobre la transparencia de las instituciones públicas», Revista Española de la Transparencia, 11: 13-20. Disponible en: https://doi.org/10.51915/ret.118.

Bob, Clifford y Sharon Nepstad. 2007. «Kill a leader, murder a movement? Leadership and assassination in social movements», American Behavioral Scientist, 50 (10): 1370-1394. Disponible en: https://doi.org/10.1177/0002764207300162.

Chaqués, Laura. 2004. Redes de politicas públicas. Madrid: CIS; Siglo Veintiuno Editores. 
Chenoweth, Erica y Maria J. Stephan. 2011. Why Civil Resistance Works. The strategic logic of nonviolent conflict. Nueva York: Columbia University Press.

Cohen, Jean L. y Andrew Arato. 1992. Civil society and political theory. Cambridge, Mass.: MIT Press.

Dür, Andreas y Dirk De Brièvre. 2007. "The Question of Interest Group Influence», Journal of Public Policy, 27: 1-12. Disponible en: https://doi.org/10.1017/S0143 $814 X 07000591$.

Ebrahim, Alnoor. 2019. Measuring Social Change. Performance and Accountability in a Complex World. Stanford, CA: Stanford University Press. Disponible en: https:// doi.org/10.1515/9781503609211.

Foley, Michael W. y Bob Edwards. 1996. "The Paradox of Civil Society», Journal of Democracy, 7 (3): 38-52. Disponible en: https://doi.org/10.1353/jod.1996.0048.

Fox, Jonathan. 2007. "The uncertain relationship between transparency and accountability», Development in Practice, 17 (4-5): 663-671. Disponible en: https://doi. org/10.1080/09614520701469955.

Fox, Jonathan. 2015. «Social Accountability: What Does the Evidence Really Say?», World Development, 72: 346-361. Disponible en: https://doi.org/10.1016/j.worlddev.2015.03.011.

García Guitián, Elena. 2016. «Representación y gobernabilidad. Una reflexión sobre el rol de los ciudadanos organizados en las democracias», en Joaquín Molins, Luz Muñoz e Iván Medina (dirs.), Los grupos de interés en España. Madrid: Tecnos.

Glaser, Barney y Anselm Strauss. 1967. The Discovery of Grounded Theory. Strategies for Qualitative Research. Chicago: Aldine. Disponible en: https://doi.org/10.1097/ 00006199-196807000-00014.

Glasius, Marlies. 2012. "Dissident writings as political theory on civil society and democracy», Review of International Studies, 38 (2): 343-364. Disponible en: https://doi.org/10.1017/S0260210511000155.

Gobierno de España. 2020. IV Plan de Gobierno Abierto 2020-2024. Madrid. Disponible en: https://cutt.ly/iR34xua.

González León, Patricia. 2021. «La senda de la transparencia en España durante la COVID-19", Revista Española de la Transparencia, 11: 21-30. Disponible en: https://doi.org/10.51915/ret.119.

Grant, Wyn. 1989. Pressure Groups, Politics and Democracy in Britain. Nueva York: Phillip Allan.

Habermas, Jürgen. 1987. The theory of communicative action, Vol. 2: Lifeworld and system: A critique of functionalist reason. Boston: Beacon Press.

Jones, Bryan D. y Frank R. Baumgartner. 2005. The politics of attention: How government prioritizes problems. Chicago: University of Chicago Press.

Kaufmann, Daniel, Aart Kraay y Massimo Mastruzzi. 2005. Governance matters IV: governance indicators for 1996-2004. Policy Research Working Paper Series, 3630. Washington D.C.: The World Bank. Disponible en: https://doi.org/10.1596/18139450-3630. 
Keck, Margaret y Kathryn Sikkink. 1998. Activists beyond Borders: Advocacy Networks in International Politics. Ithaca: Cornell University Press.

Kingdon, John W. 2010. Agendas, alternatives and public policies, updated edition (2nd ed.). Londres: Longman Publishing Group.

Klüver, Heike. 2012. "Informational Lobbying in the European Union: The Effect of Organisational Characteristics», West European Politics, 35 (3): 491-510. Disponible en: https://doi.org/10.1080/01402382.2012.665737.

Landell-Mills, Pierre. 2013. Citizens Against Corruption: Report from the Front Line. Padstow: Troubador pub LTD.

Mahoney, Chistine y Frank B. Baumgartner. 2008. «Converging perspectives on Interest-Group Research in Europe and America», West European Politics, 31 (6): 1251-1271. Disponible en: https://doi.org/10.1080/01402380802372688.

Malena, Carmen, Reiner Forster y R. Janmejay Singh. 2004. Social accountability: An introduction to the concept and emerging practice. World Bank, Social Development Paper, 76. Washington: The World Bank.

Mattoni, Alice. 2014. "The Potentials of Grounded Theory in the Study of Social Movements», en Donatella Della Porta (ed.). Methodological practices in social movement research. Oxford: Oxford University Press. Disponible en: https://doi. org/10.1093/acprof:oso/9780198719571.003.0002.

Mattoni, Alice. 2020. "The grounded theory method to study data-enabled activism against corruption: Between global communicative infrastructures and local activists' experiences of big data", European Journal of Communication, 35 (3): 265-277. Disponible en: https://doi.org/10.1177/0267323120922086.

Medina, Iván y Luz Muñoz. 2016. «La relevancia de los grupos de interés en la Ciencia Política», en Joaquín M. Molins, Luz Muñoz e Iván Medina (dirs.), Los grupos de interés en España. Madrid: Tecnos.

Molins, Joaquín M. 2016. "Los grupos de interés en España. Del “amiguismo” a la pluralidad democrática (1900-2015)», en Joaquín M. Molins, Luz Muñoz e Iván Medina (dirs.), Los grupos de interés en España. Madrid: Tecnos.

Molins, Joaquín M., Luz Muñoz e Iván Medina (dirs.). 2016. Los grupos de interés en España. Madrid: Tecnos.

Montero, José R., Richard Gunther y Mariano Torcal. (1998) «Actitudes hacia la democracia en Espańa: legitimidad, descontento y desafección», REIS, 83: 9-49. Disponible en: https://doi.org/10.2307/40184120.

Mungiu-Pippidi, Alina. 2010. "The Experience of Civil Society as an Anticorruption Actor in East Central Europe», Romanian Journal of Political Science, 10: 5-33.

O'Donnell, Guillermo. 2006. "Notes on Various Accountabilities and their Interrelations», en Enrique Peruzzotti y Catalina Smulovitz (eds.), Enforcing the rule of law: Social accountability in the new Latin American democracies. Pittsburgh: University of Pittsburgh Press.

O’Donnell, Guillermo. 2007. Disonancias: críticas democráticas a la democracia. Buenos Aires: Prometeo. 
O’Meally, Simon C. 2013. Mapping Context for Social Accountability: A Resource Paper. Washington, DC: World Bank.

Osborne, David y Ted Gaebler. 1992. Reinventing government: how the entrepreneurial spirit is transforming the public sector. Reading, MA: Addison Wesley.

Pape, Robert A. 1997. "Why economic sanctions do not work», International Security, 22 (2): 90-136. Disponible en: https://doi.org/10.1162/isec.22.2.90.

Patton, Michael Q. 2002. Qualitative research and evaluation methods (3rd ed.). California: SAGE Publications.

Peruzzotti, Enrique y Catalina Smulovitz (eds.). 2006. Enforcing the rule of law: Social accountability in the new Latin American democracies. Pittsburgh: University of Pittsburgh Press. Disponible en: https://doi.org/10.2307/j.ctt9qh5t1.

Putnam, Robert D. 1993. Making Democracy Work: Civic Traditions in Modern Italy. Princeton: Princeton University Press. Disponible en: https://doi.org/10.1515/ 9781400820740.

Putnam, Robert D. 1995. «Bowling Alone: America's Declining Social Capital», Journal of Democracy, 6: 65-78. Disponible en: https://doi.org/10.1353/jod.1995. 0002.

Rosa, Hartmut. 2020. «Cuatro niveles de auto-interpretación. Un paradigma para la filosofía social interpretativa y la crítica política», Encrucijadas, 20.

Sabatier, Paul. 1998. «The Advocacy Coalition Framework: Revisions and Relevance for Europe», Journal of European Public Policy, 5 (1): 93-130. Disponible en: https://doi.org/10.1080/13501768880000051.

Schattschneider, E. E. (1960). The Semisovereign People: A Realists View of Democracy in America. Illinois: The Dryden Press.

Strauss, Anselm L. y Juliet M. Corbin. 1998. Basics of qualitative research: Techniques and procedures for developing grounded theory (2nd ed.). California: SAGE.

Tarrow, Sidney. 1998. Power in movement. Nueva York: Cambridge University Press. Disponible en: https://doi.org/10.1017/CBO9780511813245.

Taylor, Charles. 1979. Hegel and Modern Society. Cambridge: Cambridge University Press. Disponible en: https://doi.org/10.1017/CBO9781316286630.

Tocqueville, Alexis de. 1969. Democracy in America. Nueva York: Doubleday.

Tsebelis, George. 2000. «Veto Players and Institutional Analysis», Governance, 13 (4): 441-474. Disponible en: https://doi.org/10.1111/0952-1895.00141.

Truman, David B. 1951. The Governmental Process: Political Interests and Public Opinion. Nueva York: Alfred A. Knopf.

Weinstein, Jeremy M. 2007. Inside rebellion: The politics of insurgent violence. Nueva York: Cambridge University Press. Disponible en: https://doi.org/10.1017/ CBO9780511808654.

Presentado para evaluación: 15 de junio de 2021.

Aceptado para publicación: 5 de octubre de 2021. 


\begin{abstract}
MANUEL VILLORIA manuel.villoria@urjc.es

Catedrático de Ciencia Política en la Universidad Rey Juan Carlos de Madrid (URJC), donde dirige el Observatorio en Buena Gobernanza. Tiene cinco sexenios de investigación/transferencia. Es director del máster de Alta Dirección Pública del Instituto Universitario Ortega y Gasset-UIMP y del máster en Gestión de la Seguridad, Crisis y Emergencias IUOG-URJC; doctor en Ciencia Política y Sociología por la Universidad Complutense de Madrid; licenciado en Derecho y Licenciado en Filología; fue becario Fulbright en USA, donde realizó cursos de máster y doctorado por la Indiana University. Es autor de más de doscientas publicaciones científicas. Es miembro del Consejo Científico del organismo internacional CLAD, y del Consejo asesor del CIS. Presidente del Comité de Ética del Comité Olímpico Español (COE), exsecretario de la Comisión de Ética de la UGT y miembro del Comité de Ética del Ayuntamiento de Bilbao. Cofundador y miembro de la Junta Directiva de Transparency International-España. También fue presidente de la Asociación +Democracia y es miembro de su directiva.
\end{abstract}

\title{
FERNANDO JIMÉNEZ
}

fjimesan@um.es

Catedrático de Ciencia Política y de la Administración de la Universidad de Murcia, doctor en Ciencia Política por la Universidad Complutense y doctor-miembro del Instituto Carlos III-Juan March. Fue Becario Fulbright-SAAS en el Departamento de Ciencia Política de la Universidad de California (1999). Es experto de GRECO (Grupo de Estados contra la Corrupción) del Consejo de Europa, y miembro del capítulo español de Transparency International. Supervisó los informes sobre España para el Informe anticorrupción de la UE en 2014 y 2016. Experto en temas de anticorrupción de la red TAIEX de la Comisión Europea. 